\title{
Challenges faced for micro-tunelling works in Jadaf, Dubai for long drive on large scale projects (case study)
}

\author{
Devendra Datt Bhatt ${ }^{1},{ }^{*}$ Khalil Charif ${ }^{2}$, and Rabee Rustum ${ }^{3}$ \\ ${ }^{1}$ Project Director; Gulf Petrochemical Services and Trading L.L.C (Dubai Br) \\ ${ }^{2}$ Managing Director; International Foundation Group L.L.C \\ ${ }^{3}$ Professor, Water and Environmental Engineering; Heriot Watt University (Dubai-campus)
}

\begin{abstract}
This paper presents the challenges faced during micro-tunnelling process in Emirates of Dubai. In permeable grounds, the loss of slurry increases the cutter head torque and reduces penetration rates. Overcut is formed to provide space for converging ground and enables the evenly circulation of lubricant flow on the pipe line, as such buoyancy effects of fluid lubrication act on the pipe to lessen the drag during jacking. Microtunnelling techniques are used to reduce penetration resistance within the pipe string by providing sufficient uniform overcut and continuously injecting polymer lubricants. It is also observed that as the Urban area in Dubai is surrounded by built structures and numerous underground services, a special consideration is required to protect these services especially DEWA ED Cables. Also, the high ground water table, fractures within the rock and proximity of creek makes things very difficult to reduce the water table level in launching / receiving Pit and have difficulties in breaking the hard ground within the Pit. At Wafi Interchange, proposed development for the extension of interchange had to be incorporated in the alignment and accordingly standard pipe fittings to be introduced in the alignment. There are services towards Sheikh Butti palace (launching pit side) and on the other side (receiving pit). Ongoing construction of Al Jaliliya children's hospital requires close coordination and safety related issues to be addressed prior to mobilization of heavy equipment at the proposed micro-tunnelling area. The receiving pit at Emarat petrol pump was also critical and special approval from RTA is required to close one lane at the heavy traffic along the service road, parallel to sheikh Rashid road. The removal of ground water was another challenge because near Sheikh Butti palace the drainage network was not completed and hence special arrangement was to be made to discharge the water near the creek, for which DM environment approval are to be sought.
\end{abstract}

\footnotetext{
${ }^{*}$ Corresponding author: ${ }^{1}$ harshlovely@hotmail.com
} 


\section{Introduction}

There are risks involved in sub-structural tunnelling that are to locate and identify the existing services to give way for proposed micro-tunelling and avoiding any interface or obstructions with existing services or as built structures. The poor geological condition (Low N Value) $\dagger$ and non-availability of sufficient cover can cause the surface settlement. Due to large amount of dewatering and high amount of load imposed by surrounding structures, chances of surface settlement and uneven longitudinal ground settlement increases [4]. Bore in unsuitable ground has the tendency to converse the string of the pipe including tunnelling head and the machine attached to it (known as $\mathrm{CAN}) \$$. For the sub-terrain condition in hard rock ground, holes provide more suitability and are conducive ground to micro-tunnelling procedure $[1,3$, 6]. The tendency of earth at forefront of micro-tunelling to move viciously towards sealed fitted in front of the pipe to be jacked and sophisticated slurry shield is used to overcome these failures.

Forces that are relevant to face load depend upon the soil condition and its nature. The front shield has the following advantages:

a) Safe working place for men to enter and work

b)Mounting for face stabilization device

c) A place to observe line and level

d)Adjusting the directions of string

Shield are controlled remotely and in most cases controlled by computer.

\section{Launching and receiving shaft}

In loose soil and specifically in Jadaf area where the services are quite close to launching and receiving pit, it is a challenge to make these pits. A larger amount of water is to be dewatered and special care is required to remove water only and ensure dewatering process in such a way that soil particles and other dissolved particles are minimum to avoid any future settlement, mobilization and demobilization heavy plant and equipment require special consideration and approval from government agencies to avoid any kind of disruption to the work, nearby as built structure and traffic $[1,9]$.

\section{Sheet piling}

A proper sheet piling with interlock system and vibro-hammer are used to lower the sheet pile, prior to this pre-boring is used to loosen the ground as the ground is hard after certain depth [3]. A proper designing of sheet piling is required and sufficient impeding must be done below to reduce the level, as shown in Figure 1 (a) and (b). Bracing/Wall support is to be provided per the design calculation and maximum bending moment to minimize settlement

\footnotetext{
SPT (Standard Penetration Test) Value.

$\$$ A steel sleeve attached with micro-tunelling machine head to accommodate other necessary parts required for micro-tunnelling operation.
} 


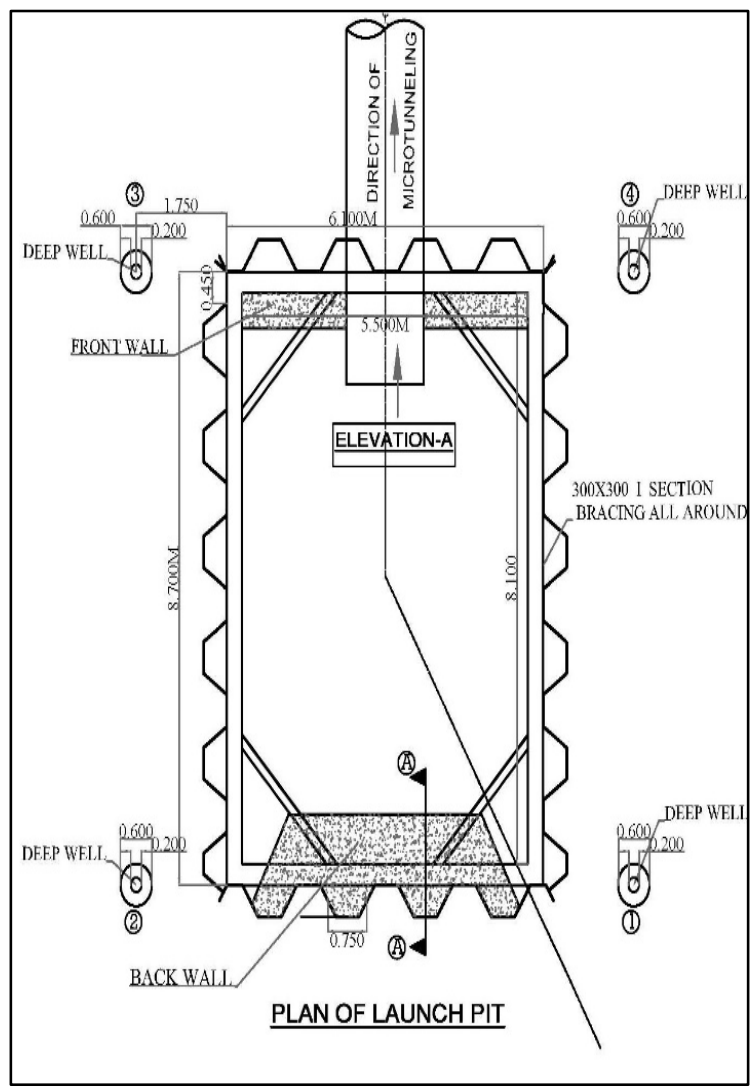

(a)

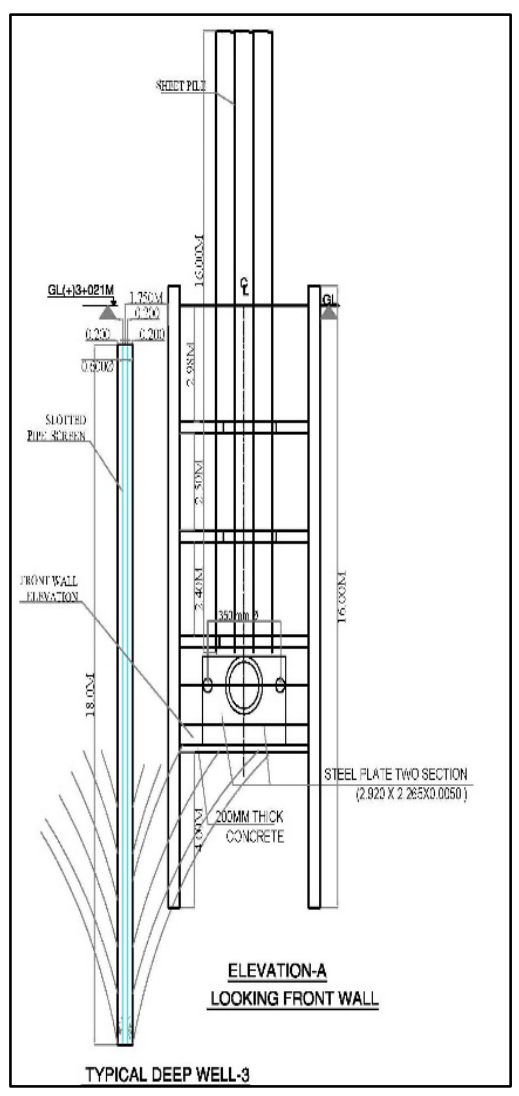

(b)

Fig. 1. (a) Plan of Launch pit and location of deep well (b) Elevation A and cross-section details of deep well and sheet pile.

If proper dewatering is not in place, then due to removal of silt or dissolved particles from the existing soil, it may cause future settlements. The soil structure in Jadaf Area is soft at a depth of 4-5 meter, and thereafter SPT value increase drastically at a depth of 10-16 meter, it is then very hard and SPT value is generally more than 100 unit, in such a hard soil it is difficult to lower the sheet pile and therefore pre-drilling is a necessity to avoid any damage to the sheet pile. Such a case is found at site (receiving pit for micro-tunelling number M01 ), which is described in Figure number 2. It can also be seen in the Figure that the pit is very close (around 6 meter) from the overhead bridge which is leading to the Business Bay and crossing Al Khail road. Therefore, to access work site, a special approval is required from RTA and special care is needed to monitor the vertical height limit [3-6,8,9-15]. As the area is very close to the existing creek, high amount of water has caused difficulty to lower down the water table in the receiving pit and therefore other related activities such as excavation and bracing work are affected. As the receiving pit is very close to the main road i.e. Al Khail road (refer Figure 2), it requires proper monitoring of spot level to check if any 
surface settlement is observed, proper designing of sheet pipe and dewatering is also required $[2,7]$.

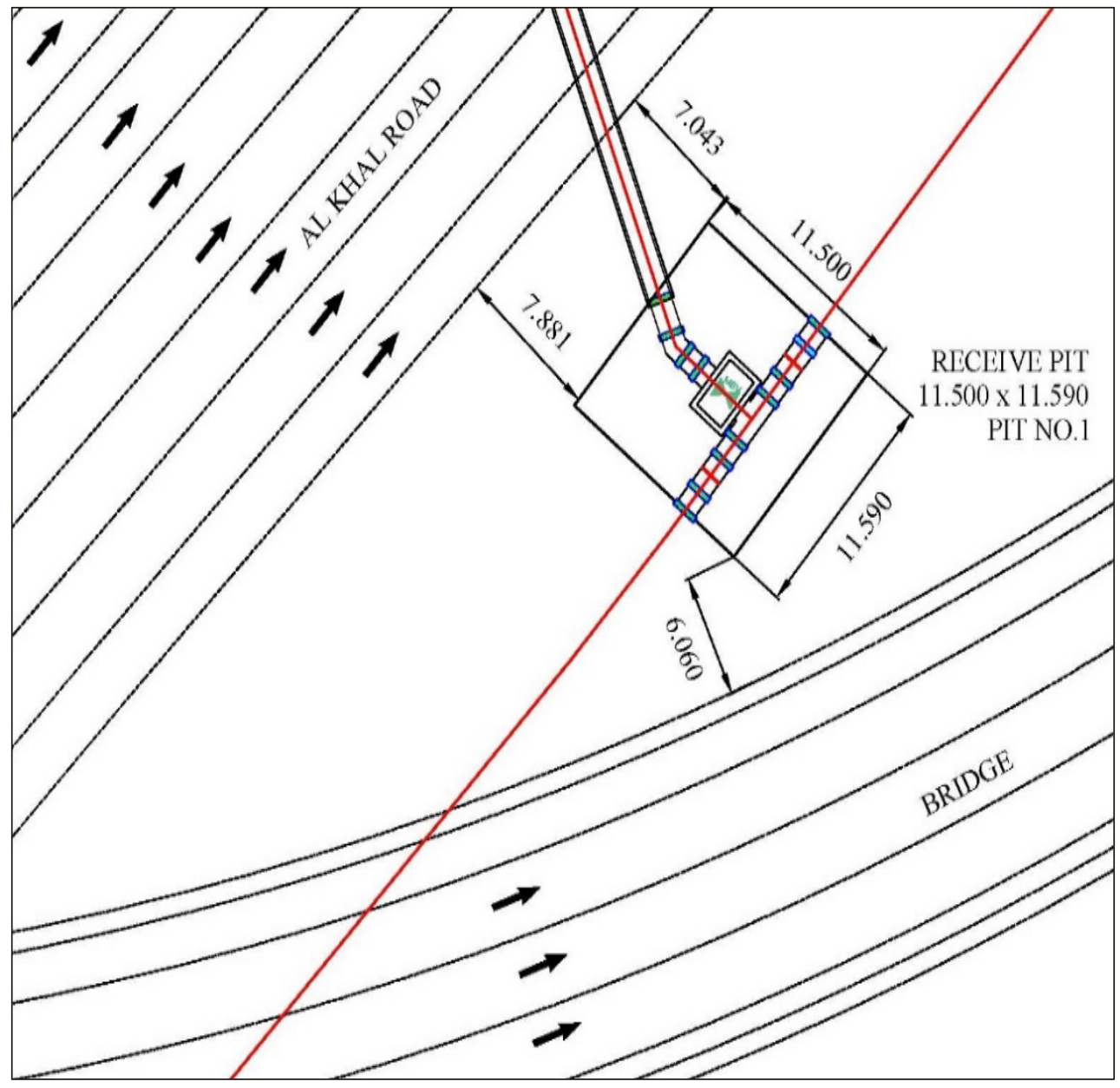

Fig. 2. Detail of Receiving pit number 1 across $\mathrm{Al}$-Khail road, with surrounding fly overbridge.

\section{De-watering}

Place as the network in Jadaf area is not readily available at the time of construction activities, therefore a special approval is required to discharge the water into the Creek. For this purpose, a proper NOC $\S$ is required from relevant department with water being tested to be submitted to the design team. Another difficult being faced is that as heavy equipment is being moved across the site, it can damage the de-watering discharge pipe and therefore it must be properly protected with steel sleeve. This is shown in Figure 3, and discharge point to the Creek is shown on the same drawing. Four numbers of deep well are provided for Pit Number 1 and locations of these deep well to be in a similar way as per Figure 1 (a). These four numbers are required due to high flow of water and in case of any failure as soil condition is very loose in this area. Similarly, Figure 4 provides the discharging location of de-watering (section 11). Special care must be considered for deep well, as particles size distribution shows that

$\S$ No Objection Certificate. 
this area has lot of fine silt content in the soil structure and to control egress silt content from soil structure and to stop them falling into deep well with water flow, surrounding

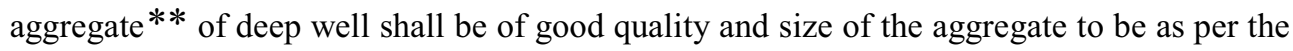
de-watering contractor's design so that silt content remains within soil structure and does not pass through de-watering system. Also, slotted pipe or vertical screen pipe (generally PVC and in special cases can be metal), as shown in Figure 1 (b) for deep well must be of good quality and as per the design [8].

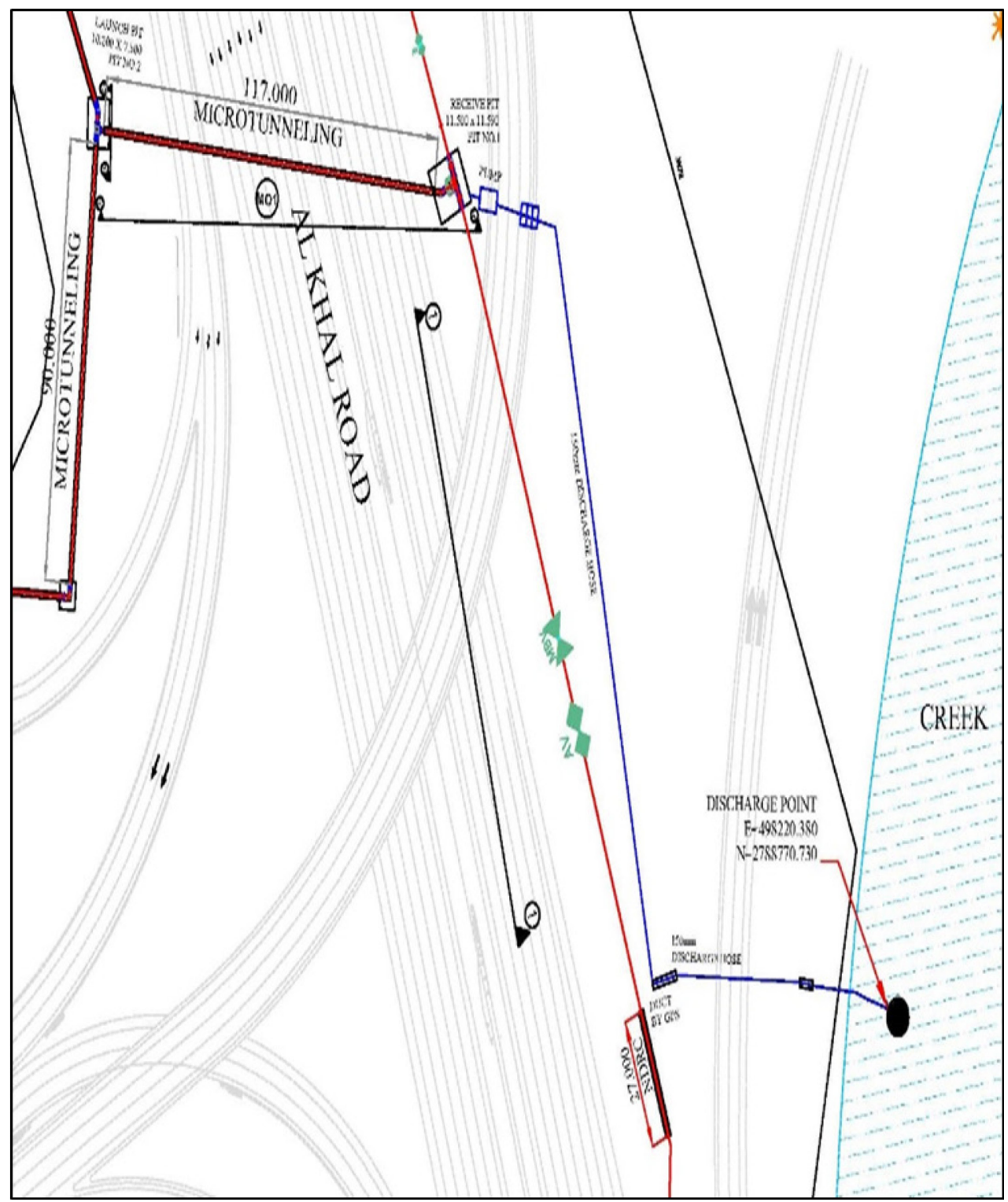

Fig. 3. Detail of de-watering network for pit no 1 and its discharge layout.

$\overline{\text { ** Fine and cleaned crushed stone particle, }}$ as per de-watering sub contractor's design. 


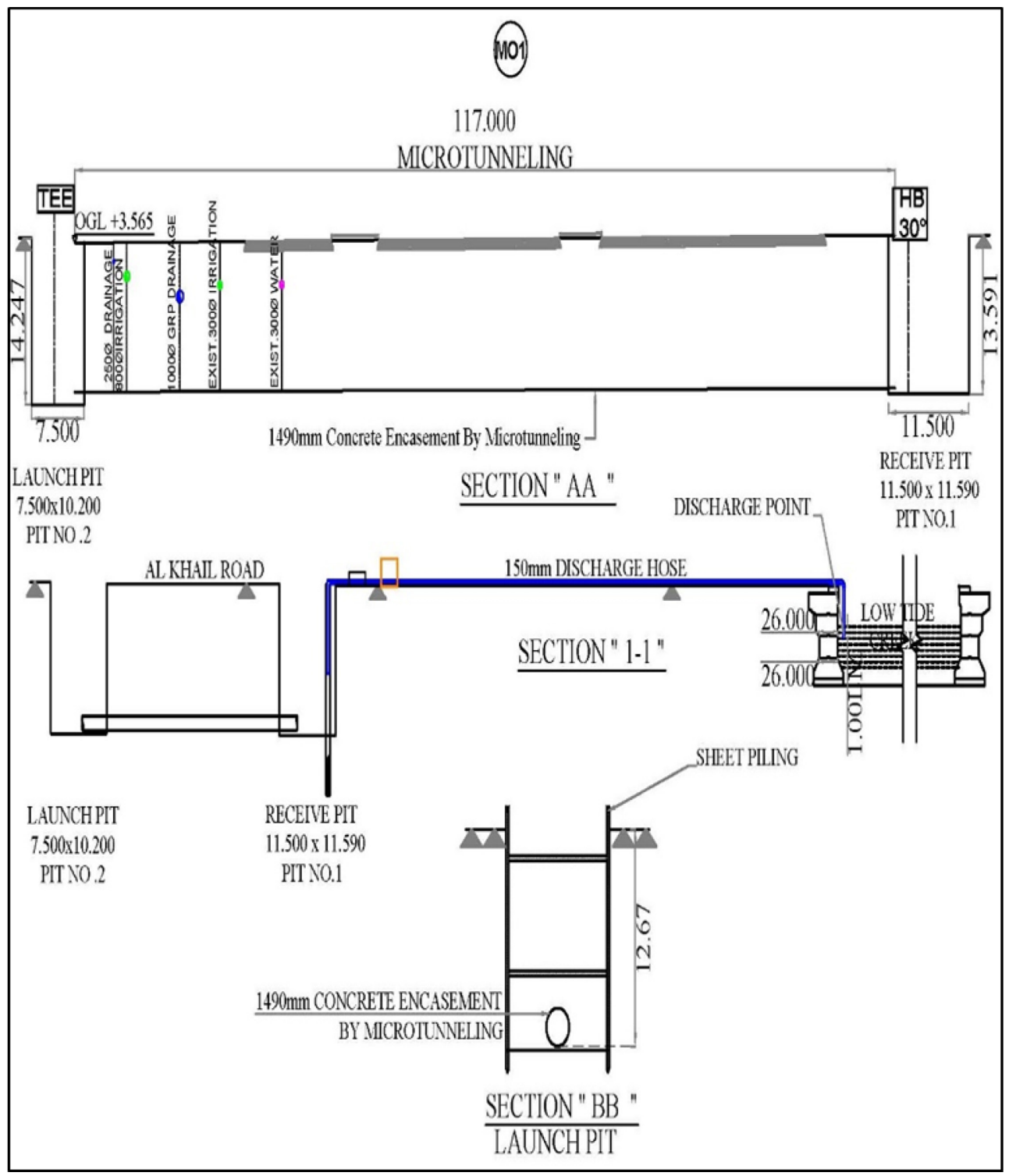

Fig. 4. Detail of de-watering network for pit number 1 and its discharge layout section 1-1, into creek.

\section{Micro-tunelling}

As micro-tunelling has several equipment's and requires working space, storage space to organize the equipment's such as, soil spool removal system, generator, pipes etc. In Jadaf area there are certain locations where it is very difficult to mobilize equipment and material, and due to the storage constrain it is decided that the piping materials will not be stored more than 6-7 pipes at a time. As the site area is in the city, therefore movement of heavy vehicles and noise is to be controlled accordingly. A special care is required for the summer time where cooling effect is necessary for the people working in the launching Pit. It is also 
necessary to control the temperature of air inside the tunnel; otherwise it can deflect laser control system and ultimately alignment of the tunnel.

In Figure 5 detail alignment of the pipeline and micro-tunnelling has been shown, to control overall movement of the traffic and other obstruction it is divided into three stages, all these are described in Figure 5.

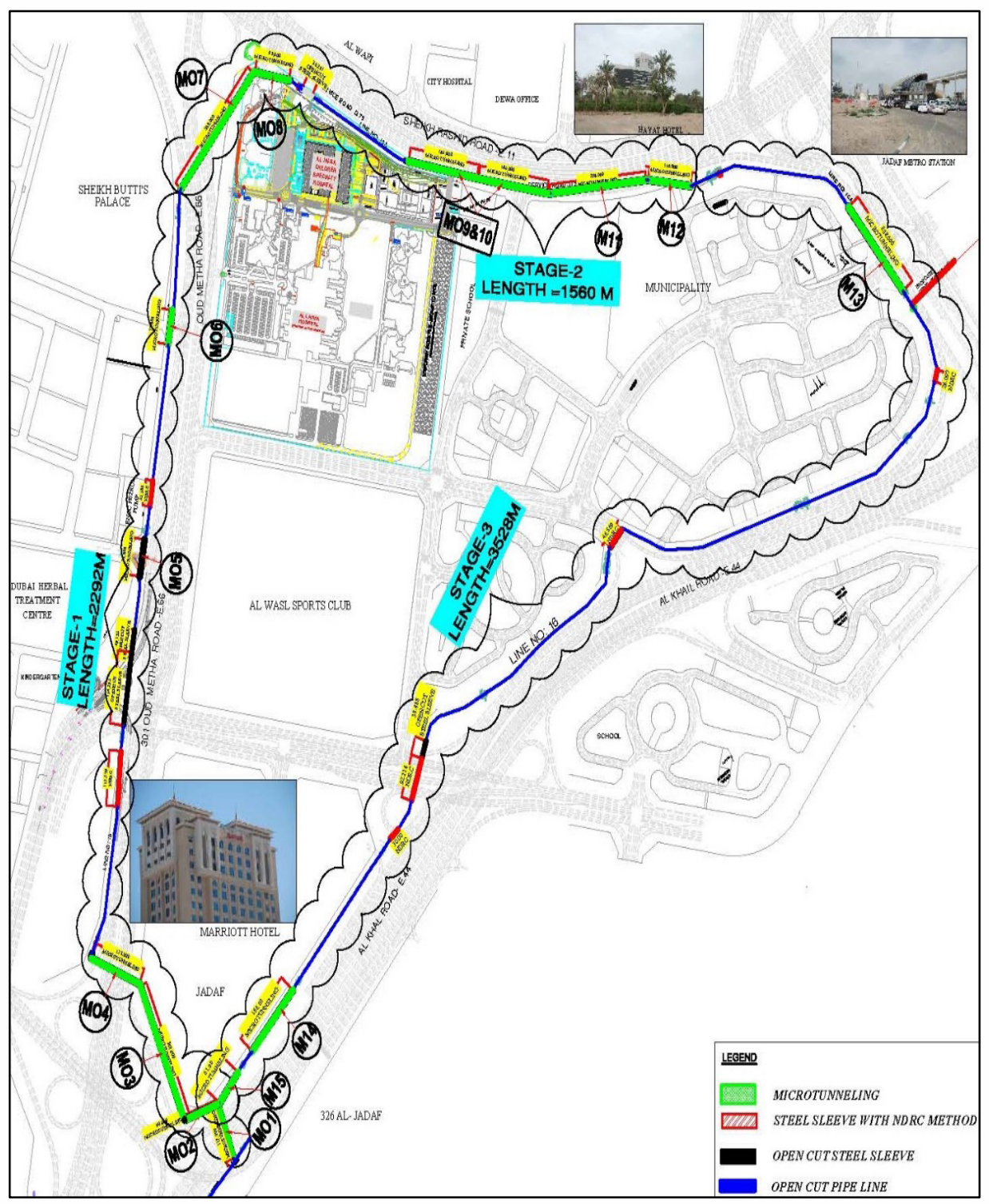

Fig. 5. Bird eye view of the study area (Jadaf- Oud Maitha - Al Khail Road).

Total micro-tunnelling works is of 2,410 meter for all the three stage for all together fifteen locations of micro-tunnelling as per Table 1 . 
Table 1. Micro-tunnelling details for 1200 diameter GRE water transmission Pipe.

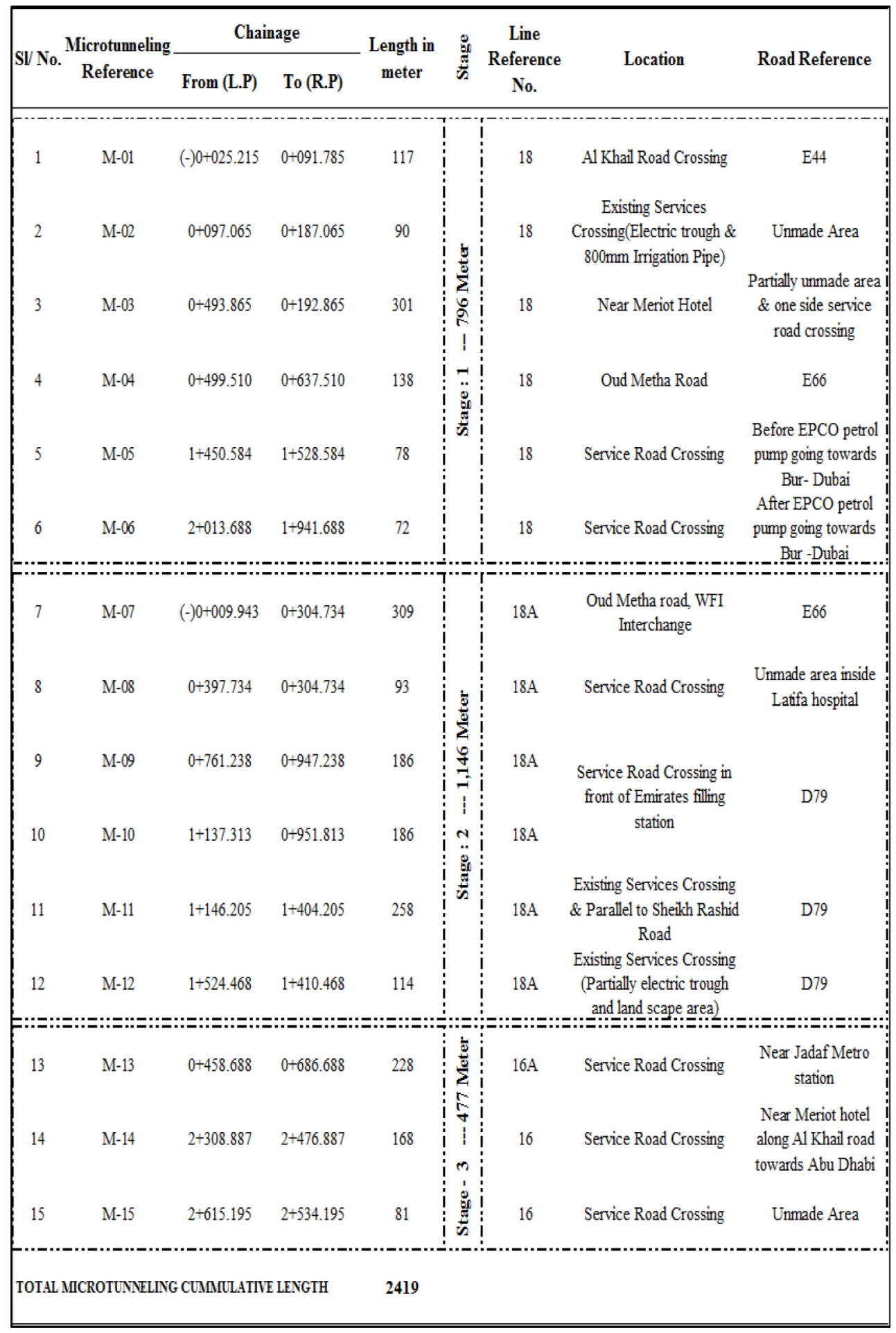




\section{Site obstructions}

There are many site obstructions and one such case is at micro-tunnelling number $9 \& 10$ where the overall length of the micro-tunelling is of 372 meter (186 meter each section joined together at mid - Pit number 5, on Figure number 6) and Receiving Pit is located at the busy service road, close to the Emarat fuel filling station. Therefore, a special permission for traffic diversion from RTA, $\mathrm{DM} \dagger \dagger$ for de-watering discharge point, Emarat fuel station for diversion of traffic, protection to their underground fuel reservoir and Horticulture for removal of grass and tree is required. Apart from this, a proper design is also required for receiving pit, movement of heavy vehicles, logistics plan for lowering and removing of sheet pile without damaging and disturbing the nearby structures, to the traffic and underground oil reservoir tank of the Emarat fuel filling station as shown in Figure 6. Similar issues were encountered near sheikh Buti palace and Al Jalilia children specialty hospital. At sheikh Buti palace where DEWA electrical services were in a close proximity to the launching pit; whereas at AL Jalila children specialty hospital, site coordination and alignment of the pipeline and micro-tunnell to incorporate standard fitting and at the same time avoid clashes to the ongoing site activities and proposed wafi interchange additional works, such as proposed pier clashing with pipe line alignment and deep excavation of the basement of the hospital and its close proximity with launching and receiving pit for micro-tunnelling reference number M07, 08, 09 and M10.

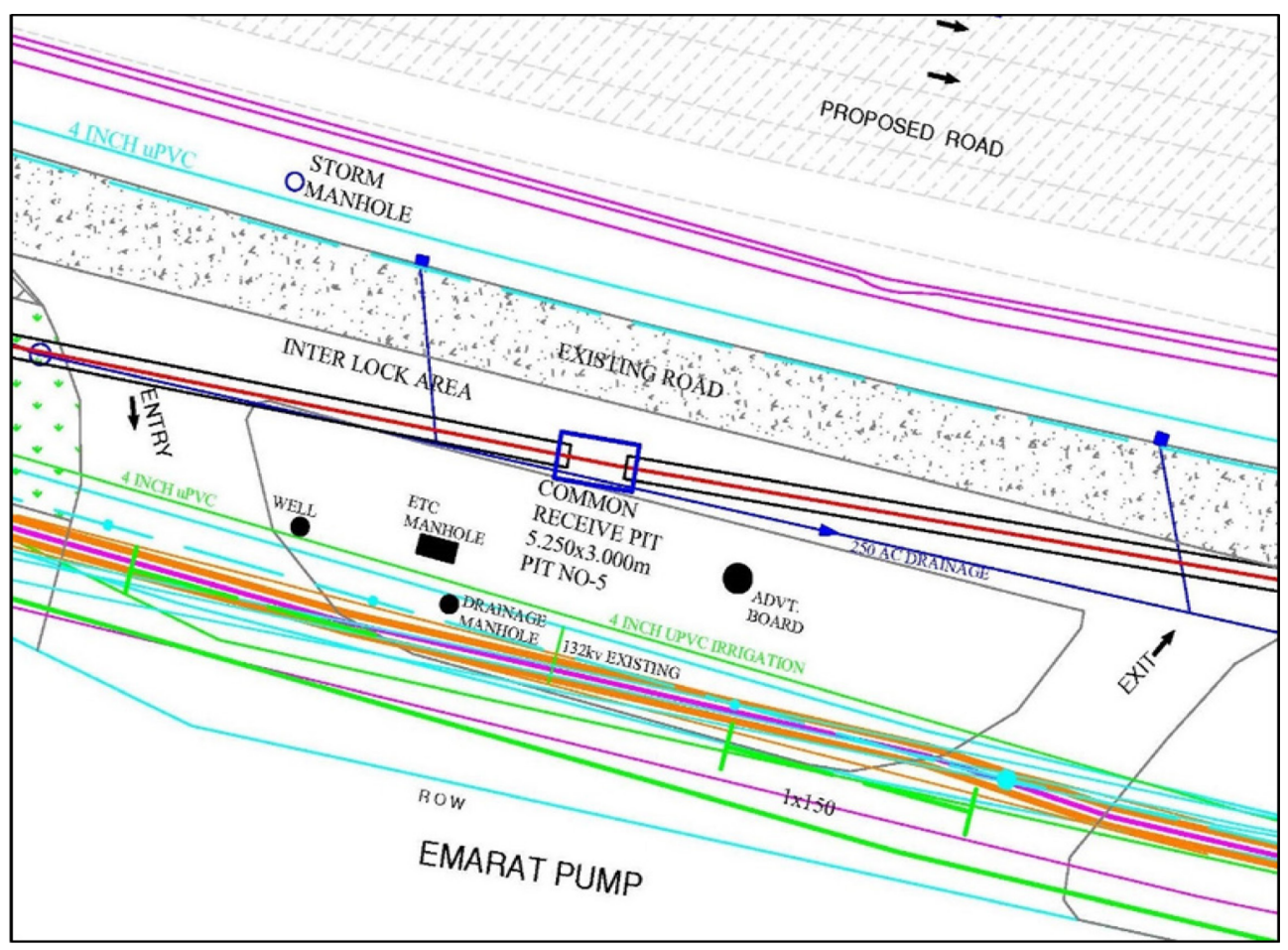

Fig. 6. Alignment of micro-tunnell $9 \& 10$ (meeting at common receiving pit number 5, proximity of the receiving pit to underground fuel oil tank and other services).

† Dubai Municipality. 


\section{Conclusion}

The present study has focused exclusively on the Jadaf area in Dubai, United Arab Emirates, in a particular pattern of the soil with specific parameter for a given O.D + t $(1490 \mathrm{~mm}$ composite pipe with concrete encashment - for I.D $\S \S 1200 \mathrm{~mm} * * *$ diameter GRE $\dagger \dagger \dagger$ pipe for main water transmission pipe line for DEWA) of the bore and accordingly the microtunnelling machine has been selected for typical soil parameter, surrounded by existing underground services and various future proposal of infrastructure. There are further regions such as crossing of water ways (canal / filled up areas etc.) and proximity of the important structure for instance hospital, hotels, educational institute etc, in a different kind of soil parameter. Similar case study is required in other areas to ascertain challenges faced during construction and the amount of surface settlement within the range predicted in theory and after effect of the micro-tunneling. It is also advisable to consider future development at designing stage itself in coordination with different agencies involved in the proposed project.

\section{References}

1. Barla, M. and Camusso, M. (2013) 'A method to design micro-tunnelling installations in randomly cemented Torino alluvial soil', Tunnelling and Underground Space Technology, 33, pp. 73-81.

2. Beard, A. N. (2010) 'Tunnel safety, risk assessment and decision-making', Tunnelling and Underground Space Technology, 25(1), pp. 91-94.

3. Bergeson, W. (2014) 'Review of long drive micro-tunneling technology for use on large scale projects', Tunnelling and Underground Space Technology, 39, pp. 66-72.

4. Camós, C. and Molins, C. (2015) '3D analytical prediction of building damage due to ground subsidence produced by tunneling', Tunnelling and Underground Space Technology, 50, pp. 424-437.

5. Choo, C. S. and Ong, D. E. L. (October 2015) 'Back - analysis and finite element modeling of jacking forces in weathered rocks', p. 10.

6. Clarke, J. A. and Laefer, D. F. (2014) 'Evaluation of risk assessment procedures for buildings adjacent to tunnelling works', Tunnelling and Underground Space Technology, 40, pp. 333-342.

7. Denver (2014) Wastewater Capital Projects Management, Standard Construction Specification. Denver, Colorado: Denver.

8. Fu, J., Yang, J., Zhang, X., Klapperich, H. and Abbas, S. M. (2014) 'Response of the ground and adjacent buildings due to tunnelling in completely weathered granitic soil', Tunnelling and Underground Space Technology, 43, pp. 377-388.

9. Giardina, G., DeJong, M. J. and Mair, R. J. (2015) 'Interaction between surface structures and tunnelling in sand: Centrifuge and computational modelling', Tunnelling and Underground Space Technology, 50, pp. 465-478.

10. Hough, C. M. and Milligan, G. W. E. (1995) Guide to best practice for the installation of pipe jacks and micro-tunnels (1 vols). Marshall Robinson Roe.

11. Knappett, J., Craig, R. F. and Craig, R. F. S. m. (2012) Craig's soil mechanics. 8th ed. edn. Abingdon, Oxon; New York: Spon Press.

\footnotetext{
$\$+$ Outer diameter of the pipeline completed by micro-tunnelling method.

$\S \S$ Internal Diameter.

*** Millimeter.

$\dagger \dagger \dagger$ Glass Reinforce Epoxy pipe.
} 
12. Ong, D. E. L. and Choo, C. S. (2016) 'Back-analysis and finite element modeling of jacking forces in weathered rocks. Tunnelling and Underground Space Technology.', 51, pp. 1-10.

13. PJA (1995) Guide to best practice for the installation of pipe jack and micro-tunnelling. London: Pipe Jacking Association.

14. Terzaghi, K. (1948) Soil Mechanics in Engineering Practice. New York: John Wiley and Sons, 1948 (1966).

15. Thomson, J. C. (1993) Pipejacking and micro-tunnelling. London; New York: Blackie Academic \& Professional. 